\title{
A new way of teaching an old subject: Pharmacy Law and Ethics
}

\author{
S Chetty, BPharm, MSc, PhD; V Bangalee, BPharm, MPharm, PhD; F Oosthuizen, BPharm, MSc, PhD \\ Discipline of Pharmaceutical Sciences, School of Health Sciences, Westville Campus, University of KwaZulu-Natal, Durban, South Africa
}

Corresponding author: V Bangalee (bangalee@ukzn.ac.za)

Background. Pharmacy educators are responsible for ensuring that students are equipped with the necessary regulatory knowledge required to deal with ethical challenges that arise in practice. Teaching methods have a strong impact on student learning, making it essential to determine how learning is influenced when changing pedagogy.

Objective. To describe students' experience and perceptions of the use of a case-based learning (CBL) activity as an adjunctive method to didactic teaching of pharmacy law and ethics.

Method. A survey was conducted among 3rd-year pharmacy students enrolled for a Pharmacy Law and Ethics course at the University of KwaZuluNatal, Durban, South Africa. The course content was delivered didactically, followed by a CBL activity for which the students were divided into groups and assigned various real-life case studies.

Results. Most of the 74 respondents (66\%) agreed that the activity was enjoyable and metacognitively useful. A majority (77\%) found the activity interactive, and $92 \%$ agreed that it enhanced their understanding of pharmacy law concepts. Eighty percent agreed that it facilitated their understanding of law and ethics concepts, and their application to real-life situations.

Conclusion. The use of CBL was beneficial to both the individual student's learning experience and the overall class learning process. More importantly, the exercise improved their metacognitive awareness, and suggests the need to consider this method of teaching as part of the formal curriculum to better equip students to deal with ethical issues that will arise in practice.

Afr J Health Professions Educ 2018;10(1):61-65. DOI:10.7196/AJHPE.2018.v10i1.714

The status of pharmacy practice as a profession is governed by its laws and ethics, which underpin the role of pharmacists and confer upon them the exclusive authority to conduct certain activities that are restricted and unique to the profession. Knowledge and understanding of ethical issues and resolutions serve to guide decisions and behaviours inherent to a pharmacist's practice. However, teaching pharmacy law has become increasingly challenging, as educators are constantly encouraged to find and implement innovative ways of teaching that will promote higher-order, critical thinking and collaborative learning, coupled with the need to increase student motivation. ${ }^{[1]}$

Instruction in the main acts and regulations that govern the practice of pharmacy in South Africa (SA) are presented in a format that is outdated and difficult to interpret, which makes comprehension of the basic concepts challenging. Experience in teaching the module has revealed that the language or legalese in which pharmacy law policy is written is unfamiliar to pharmacy students, and is more suitable to law students. In addition, the acts are fragmented, creating further difficulty for students to draw on the different aspects of the law for rational decision-making, and for its application to real-life circumstances.

This situation requires considerable effort and skill from the educator to teach students how to discern reasonable solutions to problems that they may encounter in practice. Previously, the various acts and regulations were taught to students in isolation via a predominantly didactic lecturebased format. This teaching method is often disconnected, and although lecturers try to link theory to application, it is difficult to do so by use of mere examples to illustrate the text. It also relies on the skills and expertise of the lecturer to maintain student attention for the duration of the lecture.
Students at the University of KwaZulu-Natal (UKZN), Durban, SA, are drawn from diverse backgrounds, bringing with them educational, communication and language barriers. In teaching this course, it became clear that students found the language of the law texts difficult to comprehend, interpret and apply. This created a fair amount of anxiety among learners, and called for the use of alternative teaching methods to enhance learning.

However, no standardised strategies have been designed to effectively educate students and address the challenges in this area of instruction. One method could be to supplement traditional didactic lecture-based teaching with the development and implementation of case-based learning (CBL). CBL has been defined as an innovative, discussion-based teaching method $^{[2]}$ that is student centred, and encourages learners to interactively explore complex, realistic and specific situation scenarios. ${ }^{[3]} \mathrm{CBL}$ allows students to develop critical skills and reflective judgement through reading and discussing complex, real-life scenarios. It also promotes learner-centred small-group interactive learning experiences, as opposed to large-group didactic lecture-based teacher-centred instruction. ${ }^{[1]}$

As a result, students involved in CBL tend to be more confident in practising the skills learnt during the process. ${ }^{[4]}$ A further benefit that makes this method suitable for teaching in healthcare education is that it encourages students to view all aspects of a patient's situation while handling a real case. ${ }^{[5]}$ There are various types of CBL, which include seminars, standardised patient events, web situations, medical teaching rounds, mini scenarios and directed case studies. ${ }^{[4]}$ The type of case study used depends on the aim of the course, the discipline being taught and the skills needed to be nurtured. 
At UKZN, a CBL activity was used to supplement the Pharmacy Law and Ethics course, which consisted of a series of didactic lectures. The study aimed to establish the usefulness of the exercise through a number of objectives, these being to explore the student's experience and perceptions of the use of CBL, its perceived effectiveness for learning, aspects that they enjoyed/did not enjoy about the activity, benefits of the activity on learning, and finally, to obtain suggestions on how the activity could be improved.

\section{Significance of the study}

The requirement for an adjunct to routine didactic lectures has long been appreciated by higher education institutions. This stems from growing concerns that didactic teaching alone does not encourage the right student qualities, nor does it impart lifelong respect for learning ${ }^{[6]}$ In teaching Pharmacy Law and Ethics, educators are challenged to create an interesting and engaging method of educating students about a subject that is potentially considered to have little clinical relevance. ${ }^{[7]}$ While CBL has been proven to have some success in meeting this challenge in other health professions courses, ${ }^{[6]}$ there is a lack of documented data on its use in teaching pharmacy law and ethics in SA, and at UKZN specifically. Early evaluation of the usefulness of and learner experience with CBL is therefore important to modify and enrich the current teaching methods, and to form a better learning approach with the active participation of students.

\section{Methods \\ Context}

The study involved all 3rd-year pharmacy students enrolled for the course entitled Pharmacy Law and Ethics (PHRM 355) at UKZN in 2015. Students enrolled in the course have limited exposure to pharmacy laws (they are introduced to the legal framework of the SA healthcare system in their 1 st year of study), and generally have no previous exposure to ethical issues. Students registered for the course come from diverse backgrounds in terms of religion, language, ethnicity and self-directed learning skills.

The course was developed to inform students of relevant legislation governing the practice of pharmacy. The regulatory content covered includes the Pharmacy Act 53 of 1974 and the Medicines and Related Substances Control Act (1963). In addition to law, students were introduced to Good Pharmacy Practice (GPP) standards; ethical principles, such as biomedical ethics; professional ethics; code of conduct; rules pertaining to the scope of practice of pharmacy personnel; and principles of medication scheduling.

\section{Ethical approval}

Ethical approval was obtained from the UKZN Humanities and Social Sciences Research Ethics Committee (ref. no. HSS/0354/015). Student consent was obtained prior to administering the questionnaire, with participation being voluntary and anonymity being maintained.

\section{Current teaching method}

The course has traditionally been taught via didactic lectures that introduce students to concepts, principles and their application. This has been an attractive approach for ease of information dissemination to increasingly large classes, as it allows for the economical use of staff time. However, this approach is largely teacher-centred, with minimal active interaction between lecturer and students, and between the students themselves. ${ }^{[6]}$ It further places the burden of promoting learning almost entirely on the lecturer, and thus fails to develop opportunities to develop critical thinking among learners.

\section{Intervention}

The course content was first taught didactically and then supplemented by a CBL activity session.

In this study, the 95 students were randomly divided into 11 groups of 8 or 9 students. The rationale behind the random placement of students into groups was to ensure that they mixed and shared ideas with their peers, irrespective of whether they had previously worked together. Each group was assigned a case study that reflected 'real world' ethical dilemmas that are seen in pharmacy practice. Each case included a brief overview that both established a context for the problem and identified major decisions that needed to be made. The cases required students to consider the problems from a perspective that necessitated analysis, with them being guided to suitable references to consult to solve the problem. An additional reason for modifying the structure of the course was to reinforce concepts covered in the didactic portion of the course with their application to real-practice situations.

Groups were allocated 3 weeks to discuss and analyse the assigned cases, the activity being designed to encourage communication among the group members, while promoting engagement with the theory of pharmacy law. It was hoped that this type of interactive teaching would stimulate and maintain students' interest, thereby allowing for greater participation of students in their own teaching programme. Students were required to search for relevant information to solve the case, provide supporting evidence and develop a 10 - 15-minute presentation to be delivered to the rest of the class during a tutorial session. During the presentations, the other groups were encouraged to ask questions, with discussions being concluded by the lecturer who confirmed correct answers or corrected group misconceptions. Overall group performance was assessed by the lecturer, and individual marks were adjusted based on the peer assessment of their individual contributions by their own group members.

\section{Study design}

This was a descriptive, observational study designed to report on students' experience of the use of CBL as a teaching method. Data were collected through self-administered questionnaires that were manually distributed by the educator at the end of the day of group presentations. The structured questionnaire consisted of three sections, the first being demographic details (age, gender, highest qualification). Section 2 contained 9 closedended questions that were designed to establish their perceived value of the activity on improving comprehension, application to real-life situations, as well as metacognitive abilities. It consisted of Likert-scale questions focused on the following: $(i)$ the student's experience and perceptions of the activity; and (ii) its perceived effectiveness for learning. Section 3 consisted of open-ended questions that were thematically analysed and the responses aggregated to determine: (iii) what aspects students enjoyed or (iv) did not enjoy about the activity; $(v)$ benefits of the activity on their learning; and (vi) suggestions for improvement.

\section{Data analysis}

Data were collected, captured electronically and processed using Microsoft Excel 2013 (Microsoft, USA). Descriptive statistics were generated and responses were tabled for the closed-ended questions, while the responses 
for the open-ended questions were grouped in order of prevalence. The frequency count for common comments was determined and all the repeated responses $(>10 \%)$ are reported.

\section{Results}

A total of 74 respondents (26 male, 48 female) from a class of 95 students completed the survey. The majority of students (64\%) were between 21 and 22 years of age, and $71(96 \%)$ indicated that a high school matric was their highest previous education.

Table 1 reflects responses to the closed-ended Likert-scale questions. Regarding the student responses to Section 2 pertaining to experience and perceptions of the CBL activity, two-thirds (66\%) agreed that they found the activity enjoyable, with $92 \%$ noting that it helped to improve their understanding of the law concepts. Eighty percent indicated that the activity helped them to understand and apply the concepts to real-life situations, while the majority (77\%) agreed it was interactive, with many students (69\%) reporting increased classroom involvement.

Regarding the student responses to Section 2, pertaining to its perceived effectiveness for learning, just over half (59\%) of the respondents agreed that they would rate learning high from this type of activity; however, less than half (46\%) indicated that the activity kept them focused and motivated to learn more. Seventy-three percent agreed that the activity helped to validate their own learning, while $54 \%$ felt that the activity helped them to prepare for the examinations.

The open-ended questions were analysed and separated into themes that were developed from the most frequent (>10\%) responses (Table 2).

\section{Discussion}

The responsibility that pharmacy educators face in equipping graduates with enhanced communication skills, greater problem-solving capabilities, effective critical thinking abilities, and sound decision-making skills has become increasingly important. ${ }^{[8]}$ This activity requires the use of innovative and pedagogically sound instructional strategies to facilitate the learning outcomes needed to practise in all aspects of the pharmaceutical profession. To the best of our knowledge, this study represents the first documented research into students' perspectives on the use of CBL in the teaching of pharmacy law and ethics at UKZN.

Student feedback regarding Section 2 on the experience and perceptions of the CBL activity and its perceived effectiveness for learning was generally positive. Significantly, the majority (92\%) of the students agreed that participation in the exercise helped to improve their understanding of law concepts, and many indicated that it helped them to appreciate how the various law and ethics concepts applied to real-life situations. This is encouraging, as the ability of students to attach a tangible value to the application of these scenarios to real-life situations is pertinent to the practice of pharmacy in SA. Most of the students agreed that the activity was interactive. The last four questions of the closed-ended questions explored the metacognitive responses of the students' individual learning processes. The term metacognition was first used by Flavell, and means 'thinking about thinking. ${ }^{[9]}$ Metacognition consists of two parts: knowledge of cognition and metacognitive regulation. The first part is the individual's awareness of

\begin{tabular}{|c|c|}
\hline Questions & Responses, \% \\
\hline \multicolumn{2}{|l|}{ 3. Aspects enjoyed about the activity } \\
\hline $\begin{array}{l}\text { The activity was interactive and they learnt from } \\
\text { the discussions }\end{array}$ & 31 \\
\hline Students found the activity enjoyable & 23 \\
\hline $\begin{array}{l}\text { Students perceived value to it relating to real-life } \\
\text { situations }\end{array}$ & 19 \\
\hline $\begin{array}{l}\text { It promoted team activity and working together } \\
\text { in a group }\end{array}$ & 13.5 \\
\hline \multicolumn{2}{|l|}{ 4. Aspects least enjoyed about the activity } \\
\hline Nothing to report & 22 \\
\hline $\begin{array}{l}\text { Working in groups and some members of the } \\
\text { group did not contribute }\end{array}$ & 22 \\
\hline The presentations were too long & 9.5 \\
\hline \multicolumn{2}{|l|}{ 5. Benefits of case-based learning } \\
\hline It promoted retention of information & 41 \\
\hline $\begin{array}{l}\text { Application to real-life situations increased } \\
\text { comprehension and understanding of the law } \\
\text { concepts }\end{array}$ & 38 \\
\hline It promoted learning in a different way & 12 \\
\hline \multicolumn{2}{|l|}{ 6. Students' suggestions to improve the activity } \\
\hline $\begin{array}{l}\text { Students should be allowed to choose their own } \\
\text { groups }\end{array}$ & 28 \\
\hline Students would like more examples and scenarios & 26 \\
\hline No suggestions & 15 \\
\hline
\end{tabular}

\section{Table 1. Section 2: Closed-ended questions}

\begin{tabular}{|c|c|c|c|c|}
\hline Questions & Agree, $\%$ & Neutral, \% & Disagree, \% & Skipped question, \% \\
\hline \multicolumn{5}{|l|}{ 1. Experiences and perceptions of the activity } \\
\hline I found this activity enjoyable & 66 & 31 & 3 & 0 \\
\hline This activity helped improve my understanding of different law concepts & 92 & 7 & 1 & 0 \\
\hline $\begin{array}{l}\text { The activity helped in my understanding of the application of various concepts } \\
\text { in law and ethics to real-life situations }\end{array}$ & 80 & 15 & 1 & 4 \\
\hline I found this activity interactive & 77 & 20 & 1 & 2 \\
\hline This activity increased my involvement in the classroom & 69 & 24 & 7 & 0 \\
\hline \multicolumn{5}{|l|}{ 2. Perceived effectiveness for learning } \\
\hline I would rate my learning high from this type of activity & 59 & 35 & 4 & 2 \\
\hline This activity helped me stay focused and motivated me to learn more & 46 & 46 & 8 & 0 \\
\hline This activity helped me validate my own learning & 73 & 27 & 0 & 0 \\
\hline The activity helped in preparation for my examination & 54 & 39 & 6 & 1 \\
\hline
\end{tabular}


themselves as a learner and which study method would make them more productive. The second part refers to strategies that the student employs to monitor and enhance their own learning. ${ }^{[10,11]}$ The questions in the survey probed the students' self-awareness of the activity and their perceived impact on individual learning and preparation for examinations, with two-thirds enjoying the use of this type of activity to aid their learning process. More than half of the students were cognisant that they found learning high from this type of activity. The neutral numbers were quite high in this section, which could mean that people have different ways of learning, but that with this way at least there are more opportunities for learning than the traditional way, and more students will graduate with improved understanding.

Section 3 consisted of four components, aspects they most and least enjoyed, their opinions of the benefits of CBL, and suggestions for improving this method of learning, all of which were thematically analysed owing to the nature of the open-ended questions. This feedback was valuable for future modification and tailoring of the activity to suit the targeted students and course. Regarding issues relating to their enjoyment, a common response was that they found the activity enjoyable and interactive, working together in a group and benefited from the discussions. From an educator's perspective, group work also encourages co-operative learning, where the educator becomes the facilitator rather than the expert, their role being to guide learners towards achieving their goals. $^{[12]}$

One of the fundamental aspects of teaching in the pharmacy discipline is to ensure that students achieve certain core graduate competencies, one of these importantly being the ability to collaborate and communicate in a group or team. As future healthcare practitioners, their ability to function professionally, inter-professionally and in trans-professional teams will be essential. Ideally, students upon graduation from UKZN should be respectful of individual and cultural differences, backgrounds and orientations. They should also possess the ability to prevent, negotiate and resolve interpersonal conflicts. ${ }^{[13]}$ This exercise afforded students this opportunity, to work in teams and be sensitised to the implications of working with different personalities and dynamics. It was envisaged that working in randomly selected groups would facilitate discussion, debate and the sharing of ideas to solve a problem. During case analysis, students work together to discover what they know, as well as what they needed to know about the case, thus leading to more creative resolutions. In addition, students are more open to the ideas of their fellow peers during a CBL discussion. ${ }^{[14]}$ As indicated in Tables 1 and 2, a number of students found group work and learning from others enjoyable.

Contrary to the above, group work was also found to be a theme that students did not enjoy about the activity. As in any group, friction and frustration are bound to arise when individuals are required to work together, particularly when they are randomly assigned. Some students voiced concerns about fairness, and complained about being awarded the same mark, as members of the group did not contribute equally to the activity. The use of peer assessment of their group members was used in an effort to counter this bias. ${ }^{[15]}$ In hindsight, this activity would benefit from developing a set of initial ground rules and perhaps appointing a group leader to ensure that these rules are adhered to with regard to student contribution, attendance of meetings and completion of allocated member activities. ${ }^{[16]} \mathrm{A}$ suggestion that also emerged from the open-ended questions on how to improve the activity focused on dissatisfaction with the groups, where students suggested choosing their own groups.

Another factor that hindered student enjoyment of the task was the lengthy nature of the presentations. Although students were given a stipulated time of 10 - 15 minutes per presentation, many groups exceeded this, which created the problem of poor concentration. To overcome this in the future, more stringent time-keeping will be applied, and students will be provided with instruction on how to estimate and prepare for presentations with time limits.

Responses to the open-ended question that probed the benefits of the activity for learning, included that it promoted greater retention of knowledge. The literature has shown that the process of CBL allows the student to build new knowledge based on what they have previously learnt, meaning that they can access previous knowledge related to the case and, with further effort, find the answer. ${ }^{[2]}$ This self-discovery improves their retention, as opposed to them memorising facts or lecture notes. ${ }^{[2]}$ In addition, the students felt that they learnt from the discussions that were generated on the topic. They also perceived value in the application of the law to real-life situations, indicating that case studies based on real-life situations also promote the use of course content knowledge, and improve decision-making and knowledge retention.

The activity was also intended to make learning enjoyable and interactive, thereby allowing students to take more ownership for their own learning and not merely be passive participants. From Edgar Dale's ${ }^{[17]}$ cone-ofexperience model, it is theorised that people tend to retain knowledge more productively if they were contributors rather than mere observers. According to Dale's model, in a lecture, people tend to recollect $\sim 10 \%$ of what they read, $20 \%$ of what they hear, $30 \%$ of what they see, $50 \%$ of what they see and hear, $70 \%$ of what they say and write, and $90 \%$ of what they do, i.e. actively participate. ${ }^{[17]}$ One of the themes that emerged from the openended section relates to the value of the activity for learning, as it promoted learning in a different way, using visual and verbal methods and not only reading. Active learning is a process by which students are participants in their own learning process. Different approaches to active learning include co-operative, problem-based, team-based, case-based, ability-based and assessment-based learning. ${ }^{[18]}$ Dividing students into groups and assigning them real-life problems to solve and to present to the class tap into the teambased learning and CBL approaches. ${ }^{[18]}$

Although not one of the core objectives of the study, it was ascertained that an additional core competency that was gained in the study was communication skills. Developing communication competencies in the pharmacy curriculum should not be limited to teaching counselling and interpersonal skills, but should also enable students to foster confidence in developing public speaking. Presenting their findings to their peers provided students with the opportunity to practise their public-speaking skills in a safe and supportive setting. ${ }^{[19]}$

At a national level, accreditation bodies have recommended a paradigm shift from instructional to learning-based teaching. ${ }^{[13]}$ The 'instructional paradigm' or 'talk to chalk' is primarily a lecture-based one-way flow of information, whereas in the 'learning paradigm', students partner in the creation of learning. It facilitates students taking responsibility for their own learning and makes them more independent thinkers. ${ }^{[20]}$ SA pharmacy law entails the teaching of a large subject content, with the acts and regulations often being written in isolation, which makes it difficult to understand their 
application. During this exercise, students were encouraged to engage with the literature to find plausible solutions from within SA law texts. Students' responses revealed that the use of the case studies made them search for answers, and in so doing, research a topic further.

\section{Study limitations}

The study reported on student experience of CBL to teach the 3rd-year Pharmacy Law and Ethics course module; hence, the true appropriateness of incorporating CBL either as a replacement or in conjunction with didactic lecture-based teaching for other modules remains unclear. The second limitation was that the study did not assess the effectiveness of using CBL as a supplement to didactic teaching. This would have helped to ascertain if this blend of teaching would enhance learning outcomes appropriate for this particular institution in terms of subject matter and student composition.

\section{Recommendations}

This research would benefit from further studies exploring the relationship between the use of CBL and results from student assessment grades to better determine the impact of this teaching strategy. In addition, exploring the reasons for those who did not find it beneficial needs to be established in terms of school background and preparedness of independent and critical thinking.

\section{Conclusion}

The results of the study regarding the experience of using a CBL activity to teach an aspect of Pharmacy Law and Ethics reveal that this teaching strategy is perceived as a useful adjunct to the traditional didactic teaching of this subject. The student feedback suggests that CBL has a role to play in enhancing learning, and that understanding the reasons for some students not feeling that it added to their learning experience would be a valuable tool to teaching law and ethics to future pharmacy students, this being essential to prepare them to deal with ethical challenges that arise in practice.

Acknowledgements. The authors are thankful to Ms Carin Martin for all her invaluable advice and editorial support.

Author contributions. SC was responsible for the conceptualisation, data collection and write-up of the article. VB and FO assisted in data analysis and the final write-up of the manuscript.
Funding. The research reported in this publication was supported by the Fogarty International Center (FIC), National Institutes of Health (NIH) Common Fund, Office of Strategic Coordination, Office of the Director (OD/OSC/CF/NIH), Office of AIDS Research, Office of the Director (OAR/NIH), and National Institute of Mental Health (NIMH/NIH) of the NIH under Award Number D43TW010131. The content is solely the responsibility of the authors and does not necessarily represent the official views of the NIH.

Conflicts of interest. None.

1. Jesus A, Cruz A, Gomes MJ. Case based, learner centered approach to pharmacotherapy. Proceedings from EDULEARN11 Conference, 4 - 6 July 2011, Barcelona, Spain. https://repositorium.sdum.uminho.pt/ from EDULEARN11 Conference, 4 - 6 July 2011, Barcelona, Spain.

2. Hale S. Politics and the real world: A case study in developing case-based learning. Eur Polit Sci 2006;5(1):8496. https://doi.org/10.1057/palgrave.eps.2210060

3. Chi-Wan LY, Lopez-Nerney S. Using case-based learning to enhance awareness of communication principles: An exploratory study. Reflect Engl Lang Teach 2005;4:47-65.

4. Thistlethwaite JE, Davies D, Ekeocha S, et al. The effectiveness of case-based learning in health professional education. A BEME systematic review: BEME Guide No. 23. Med Teach 2012;34(6):e421-e444.

5. Richards PS, Inglehart MR. An interdisciplinary approach to case-based teaching: Does it create patient-centered and culturally sensitive providers? J Dent Educ 2006;70(3):284-291.

6. Osinubi AA, Ailoje-Ibru KO. A paradigm shift in medical, dental, nursing, physiotherapy and pharmacy education: From traditional method of teaching to case-based method of learning - a review. Ann Res Rev Bio 2014;4(13):2053-2072. https://doi.org/10.9734/arrb/2014/9053

7. Bess DT, Taylor J, Schwab CA, Wang J, Carter JA. An innovative approach to pharmacy law education utilizing mock board of pharmacy meeting. Innovations Pharm 2016;7(1):9. https://doi.org/10.24926/iip.v7i1.419

8. Fisher RC. The potential for problem-based learning in pharmacy education: A clinical therapeutics course in diabetes. Am J Pharm Educ 1994;58(2):183-189.

9. Flavell JH. Metacognition and cognitive monitoring: A new area of cognitive-developmental inquiry. Am Psycho 1979;34(10):906-911. https://doi.org/10.1037//0003-066x.34.10.906

10. Lai ER. Metacognition: A literature review. 2011. images.pearsonassessments.com/images/tmrs/Metacognition Literature_Review_Final.pdf (accessed 9 November 2017).

11. Livingston JA. Metacognition: An overview. 1997. http://www.gse.buffalo.edu/fas/shuell/CEP564/Metacog.htm (accessed 9 November 2017).

12. Bitzer E. Cooperative learning. In: Gravetts S, Geyser H, eds. Teaching and Learning in Higher Education. Pretoria: Van Schaik, 2004.

13. Health Professionals Council of South Africa. Core competencies for undergraduate students in clinical associate, dentistry, and medical teaching and learning programmes in South Africa. Pretoria: HPCSA, 2014.

14. Waterman MA, Stanley ED. Investigative case-based learning: Teaching scientifically while connecting science to society. Invention and impact: Building excellence in undergraduate Science, Technology, Engineering and
to Mathematics (STEM) education, successful pedagogies. Am Ass Adv Sci 2004:55-60.

15. Tollefson E. Evaluating peer contributions to group work. MA thesis. New York: West Point, Center for Faculty Excellence, US Military Academy, 2015:1-11. http://www.usma.edu/cfe/Literature/Tollefson_15.pdf (accessed \& Excellence, US Military Academy, 2015:1-11. http://www.usma.edu/ce/Literature/Tollefson_15.pdf (accessed

16. Haworth IS, Eriksen SP, Chmait SH, et al. A problem based learning, case study approach to pharmaceutics: Faculty and student perspectives. Am J Pharm Educ 1998;62(4):398-405

17. Dale E. Audio-Visual Methods in Teaching. New York: Dryden Press, 1946

8. Gleason BL, Peeters MJ, Resman-Targoff BH, et al. An active-learning strategies primer for achieving abilitybased educational outcomes. Am J Pharm Educ 2011;75(9):186. https://doi.org/10.5688/ajpe759186

19. Luiz AJA, Zeszotarski P, Ma C. Developing pharmacy student communication skills through role-playing and active learning. Am J Pharm Educ 2015;79(3):44. https://doi.org/10.5688/ajpe79344

20. Barr R, Tagg J. From teaching to learning: A new paradigm for undergraduate education. Change 1995;27(6):13-26. https://doi.org/10.1080/00091383.1995.10544672

Accepted 12 September 2017 